\title{
Expression of an activated Notch-related int-3 transgene interferes with cell differentiation and induces neoplastic transformation in mammary and salivary glands
}

\author{
Chamelli Jhappan, ${ }^{1}$ Daniel Gallahan, ${ }^{2}$ Cheryl Stahle, ${ }^{1}$ Eugene Chu, ${ }^{1}$ Gilbert H. Smith, ${ }^{2}$ \\ Glenn Merlino, ${ }^{1,3}$ and Robert Callahan ${ }^{2}$
}

Laboratories of ${ }^{1}$ Molecular Biology, and ${ }^{2}$ Tumor Immunology and Biology, Division of Cancer Biology, Diagnosis and Centers, National Cancer Institute, National Institutes of Health, Bethesda, Maryland 20892 USA

Expression of the int-3 locus is activated in mouse mammary tumors as a consequence of insertional mutagenesis by the mouse mammary tumor virus (MMTV). Integration of the MMTV provirus into the int-3 locus promotes the transcription and translation of flanking cellular int-3 sequences sharing significant homology with the intracellular domain of the neurogenic Notch gene of Drosophila, and with the yeast cell cycle regulatory genes $c d c 10$ and SWI6. To determine the in vivo consequences of activated int-3 expression, transgenic mice were generated harboring a genomic tumor DNA fragment consisting of the MMTV LTR and the flanking cellular int-3 sequences. All six int-3 founder transgenic mice and the progeny of one established line exhibited similar dramatic phenotypic abnormalities in tissues in which the transgene was expressed. Focal and often multiple poorly differentiated mammary and salivary adenocarcinomas appeared in the majority of transgenic mice between 2 and 7 months of age. Significantly, mammary glands were arrested in development and were lactation deficient in all female int-3 mice. The salivary glands, glands of the nasal mucosa and maxillary sinus, the extraorbital lacrimal glands, and the Harderian glands of juvenile and adult transgenic mice all contained proliferating immature ductule cells and were incompletely differentiated. In addition, all male int-3 transgenic mice were sterile, apparently the result of severe hyperplasia of the epididymis. These findings demonstrate in vivo that expression of the activated Notch-related int-3 gene causes deregulation of normal developmental controls and hyperproliferation of glandular epithelia.

[Key Words: cdc10; ductular hyperplasia; male sterility; lactation deficiency; MMTV]

Received November 22, 1991; revised version accepted January 3, 1992.

The mouse mammary tumor virus (MMTV) genome does not contain a known oncogene. Instead, it appears to induce mammary tumors in acutely infected mice by acting as an insertional mutagen (Varmus 1982). Mammary tumor development results from the clonal outgrowth of tumor cells that frequently contain an MMTV viral genome integrated at one or more specific regions (int loci) of the cellular genome. Viral integration at these int loci results in the activation of expression of flanking cellular sequences. The first two such loci characterized at a molecular and biological level were int-1 (Nusse and Varmus 1982), which is the mouse homolog (Wnt-1) of the Drosophila segment polarity gene wingless (Rijsewijk et al. 1987), and int-2 (Dickson et al. 1984|, which is a member of the fibroblast growth factor

${ }^{3}$ Corresponding author.
(FGF) gene family (Dickson and Peters 1987). Transgenic mice containing an MMTV long terminal repeat (LTR)activated Wnt-1 or int-2 transgene commonly develop mammary alveolar hyperplasia and have an increased incidence of sporadic mammary carcinomas that develop in a strain-specific manner (Tsukamoto et al. 1988; Muller et al. 1990).

Previously, we have described an additional common insertion site for MMTV in mouse mammary tumors, designated int -3 , which is genetically unrelated to Wnt-1 or int-2 (Gallahan and Callahan 1987). MMTV integration at the int -3 locus activates, by promoter insertion, the transcription of a novel truncated $2.3-\mathrm{kb}$ cellular int-3 RNA species, which is initiated from within the viral 3' LTR sequence. The deduced amino acid sequence of the MMTV promoter-activated int-3 gene product (Robbins et al. 1992) is characterized by the presence of six tandem copies of a 33-amino-acid repeat motif orig- 
inally described in the yeast $c d c 10 / S W I 6$ cell-cycle transcriptional regulatory proteins (Aves et al. 1985; Breeden and Nasmyth 1987a). This repeat sequence has also been found in several proteins involved in cell fate determination, cellular differentiation, and transcriptional regulation including Notch (Wharton et al. 1985), lin-12 (Yochem and Greenwald 1989), glp-1 (Yochem and Greenwald 1989), fem-1 (Spence et al. 1990), ankyrin (Lux et al. 1990), bcl-3 (Ohno et al. 1990), NF-кB/KBF1 (Bours et al. 1990; Kieran et al. 1990), and GABPß (LaMarco et al. 1991). In addition, like the Notch and lin-12 proteins, the $c d c 10 / S W I 6$ repeat sequences in the int-3 protein are bounded by clusters of proline, glutamic acid, serine, and threonine residues, referred to as PEST sequences, which are thought to be targets for proteolysis (Rogers et al. 1986). The Notch gene of Drosophila encodes a transmembrane protein that is required for cellcell interactions that play a pivotal role in determining neurogenic cell fate during embryonic development (Greenspan 1990). The nucleotide sequence of the activated int-3 RNA transcript is most related to the region of the Notch gene that encodes the intracellular domain of the protein (57-63\% identity with Drosophila, Xenopus, rat, and human homologs) (Wharton et al. 1985; Coffman et al. 1990; Ellisen et al. 1991; Weinmaster et al. 1992).

To assess the pathological consequences of activated int -3 expression in vivo, transgenic mice were developed that contain a mammary tumor DNA fragment composed of the $3^{\prime}$ end of the MMTV genome and the flanking cellular sequences from which the $2.3-\mathrm{kb}$ int-3 RNA species is transcribed. In the female transgenic founders and mice from the one established line (FF1), alveolarlobular development and penetration of the mammary fat pad by ductal epithelium were retarded dramatically. However, histological inspection of the mammary epithelium revealed areas of intraductal hyperplasia. Both female and male int -3 transgenic mice developed focal adenocarcinomas of the mammary and salivary glands. In general, glandular epithelia in tissues expressing acti- vated int -3 were characterized by the presence of severe ductular hyperplasia.

\section{Results}

\section{Generation of int-3 transgenic mice}

Transgenic mice were created to determine, in vivo, the biological effect of activated int-3 gene expression on mammary gland development and tumorigenesis. A 7.5kbp EcoRI genomic fragment derived from a Czech II mammary tumor (Gallahan and Callahan 1987) was used to generate the transgenic mice (Fig. 1A). This fragment contains $1.3 \mathrm{kbp}$ of MMTV env, $1.3 \mathrm{kbp}$ of $3^{\prime}$ LTR sequences, and $4.9 \mathrm{kbp}$ of int-3 flanking genomic cellular sequences. The int- 3 cellular sequences contain the entire coding region for the truncated $2.3-\mathrm{kb}$ int-3 tumorspecific RNA species. The MMTV LTR serves as the promoter, and the polyadenylation signal is located 100 bases from the 3' end of the genomic fragment.

The 7.5-kbp fragment was microinjected into one-cell FVB/N mouse embryos, which were subsequently transferred to CD1 foster mothers to complete development. Four male (AM3, EM3-1, FM2, and HM5) and two female (FF1 and GF1) transgenic founders were generated. Southern blot analysis (Fig. 1B and data not shown) showed that int 3 founders contained from one to four copies of the transgene per haploid genome.

All int -3 male founders proved to be sterile. The FF1 female had not bred successfully when she developed multiple mammary tumors. Therefore, she was superovulated and mated with a nontransgenic FVB male, and the resulting 1-day-old embryos were recovered and transferred into a nontransgenic foster female. From the resulting litter, a single line of int- 3 transgenic mice (FF1) was established in which the transgene was transmitted in a typical Mendelian fashion. The GF1 female founder was mated successfully and carried her pups to term; however, the pups were found dead with little or no milk in their stomachs, suggesting that their trans-
Figure 1. Activated int-3 transgene structure. $(A)$ The 7.5-kbp MMTV-int-3 EcoRI microinjection fragment contains MMTV envelope (ENV) and $3^{\prime}$ LTR sequences (stippled boxes), and a fragment corresponding to the truncated carboxyl portion of the mouse int -3 gene product (Gallahan and Callahan 1987). This int-3 genomic DNA includes eight exons (open boxes) and seven introns (thick black lines). (R) EcoRI, (B) BamHI. The arrow indicates the start of transcription. The locations of the cdc10 repeats and the $21 / 22$ DNA used as hybridization probes for Southern and Northern analyses are indicated. (B) Southern blot analysis showing release of a transgenespecific, 3.6-kbp BamHI fragment $(\mathrm{T})$ in transgenic $(+1$ but not in nontransgenic $(-)$ progeny of the FF1 int-3 founder; (E) the endogenous 2.0-kbp mouse int-3 gene fragment generated upon digestion with BamHI. (C) Northern blot analysis of total RNA isolated from FF1 mammary tumor isograft (Tu) and heart (He). The locations of RNA markers are shown at right.

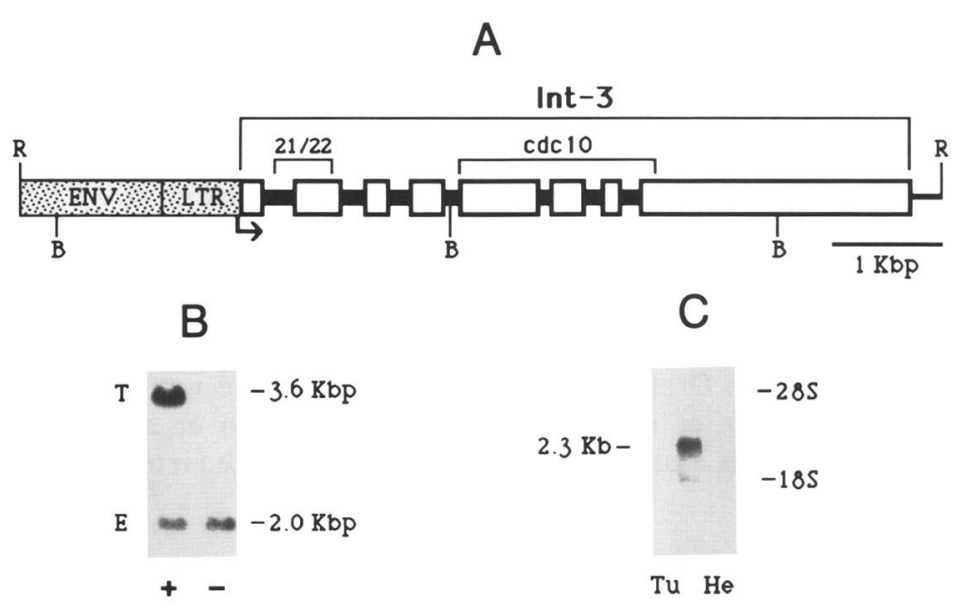


genic mother could not lactate. Subsequent histological analysis of her mammary glands confirmed that their development was incomplete and both alveolar and ductal structures were sparse.

\section{Development and neoplasia of the int -3} mammary gland

The inguinal mammary glands of the 7-month-old virgin FF1 founder and 5-month-old parous GF1 founder were developed incompletely, exhibiting a truncated version of the normal glandular penetration of the mammary fat pad (Fig. 2, cf. A with B). Histological examination of the truncated int -3 mammary gland indicated the absence of end buds, specialized structures that are instrumental in the penetration of epithelial ductal structures throughout the mammary fat pad. In parous transgenic FF1 females, lobular-alveolar development was morphologically and functionally incomplete. Secretory lobules and alveoli were largely missing in mammary glands of these parous females; however, ductal penetration of the mammary fat pad was much more extensive than in virgins (data not shown).

Hyperplastic nodular lesions were observed at multiple sites in the fat pad of the FF1 founder (Fig. 2C,D). Frank tumors of the mammary gland developed in four (three males and one female) of the six int-3 founders between 5 and 7 months of age (Table 1). FF1 progeny mice also developed mammary adenocarcinomas (Fig. $2 \mathrm{E}$ ), one as early as 7 weeks of age. These adenocarcinomas were frequently found in glands that also contained numerous ductal hyperplasias (Fig. 2E, F). Female mice developed multifocal neoplastic lesions in multiple mammary fat pads. For example, the female FF1 founder was afflicted simultaneously with advanced, poorly differentiated, multifocal mammary adenocarcinomas of the neck and thorax in five of six glands (R1, R2, R3, L2, and L3). That these mammary tumors were malignant was demonstrated by their aggressive growth when injected subcutaneously into nontransgenic FVB females (data not shown). Lung metastases were observed in four of seven FF1 line females bearing multiple mammary tumors, and in nontransgenic FVB recipient mice into which int-3 mammary tumor tissue had been transplanted.

\section{Development and neoplasia of the int-3 salivary gland}

Severe ductular hyperplasia and incomplete differentiation characterized the major and minor salivary glands of virtually all juvenile and adult int -3 mice. The proliferating ductules appeared to consist of immature cell types. Areas of differentiated acini and/or larger mature ductules could be found within these large hyperplastic regions. Figure 3 demonstrates hyperplastic lesions of the sublingual (B), submandibular (C), and parotid (D) adult transgenic salivary glands. Occasionally, serous metaplasia was observed in the sublingual gland /data not shown). In contrast, nontransgenic salivary glands exhibited normal serous and mucous cell differentiation (Fig. 3A).

Advanced salivary adenocarcinomas were observed in founders FM2, EM1-3, and AM3 between 2 and 6 months of age, as well as in male and female progeny of line FF1 (Table 1). The origin of these tumors has not been clearly established. Typically, the parotid gland was conspicuously absent from histologic preparations of salivary tumors, suggesting that adenocarcinomas arose from this tissue. However, tumors from some other int-3 transgenic mice appear to have arisen from all three major salivary glands. Tumor cells were often arranged in a tubular pattern (Fig. 3E), were poorly differentiated, and

Table 1. Summary of phenotypic abnormalities in int-3 transgenic mice

\begin{tabular}{|c|c|c|c|c|c|c|c|}
\hline Founder & Sex & Mammary gland & Salivary gland & $\begin{array}{l}\text { Harderian/ } \\
\text { lacrimal } \\
\text { glands }^{\mathbf{a}}\end{array}$ & $\begin{array}{l}\text { Nasal mucosal/ } \\
\text { submucosal } \\
\text { glands }\end{array}$ & Epididymis & $\begin{array}{l}\text { Male } \\
\text { reproduction }\end{array}$ \\
\hline AM3 & $M$ & $\mathrm{NSL}^{\mathrm{b}}$ & $\begin{array}{l}\text { hyperplasia/ } \\
\text { adenocarcinoma }\end{array}$ & hyperplasia & hyperplasia & ND & sterile \\
\hline EMI-3 & M & adenocarcinoma & $\begin{array}{l}\text { hyperplasia/ } \\
\text { adenocarcinoma }\end{array}$ & hyperplasia & $\begin{array}{l}\text { hyperplasia/ } \\
\text { adenoma }\end{array}$ & hyperplasia & sterile \\
\hline FFI & $\mathrm{M} / \mathrm{F}^{\mathrm{c}}$ & $\begin{array}{l}\text { adenocarcinoma/ } \\
\text { abnormal } \\
\text { development/ } \\
\text { nonlactating }\end{array}$ & $\begin{array}{l}\text { hyperplasia/ } \\
\text { adenocarcinoma }\end{array}$ & hyperplasia & hyperplasia & hyperplasia & sterile \\
\hline FM2 & $M$ & adenocarcinoma & $\begin{array}{l}\text { hyperplasia/ } \\
\text { adenocarcinoma }\end{array}$ & ND & ND & ND & sterile \\
\hline GF1 & $\mathrm{F}$ & $\begin{array}{l}\text { hyperplasia/ } \\
\text { abnormal } \\
\text { development/ } \\
\text { nonlactating }\end{array}$ & hyperplasia & ND & ND & NA & NA \\
\hline HM5 & $\mathbf{M}$ & NSL & hyperplasia & hyperplasia & hyperplasia & hyperplasia & sterile \\
\hline
\end{tabular}

${ }^{a}$ Hyperplasias of either the Harderian or lacrimal gland are reported here.

bAbbreviations: (NSL) No significant lesions; (ND) not determined; (NA) not applicable.

'FFI was the only int-3 line established, so both males and females could be analyzed. 

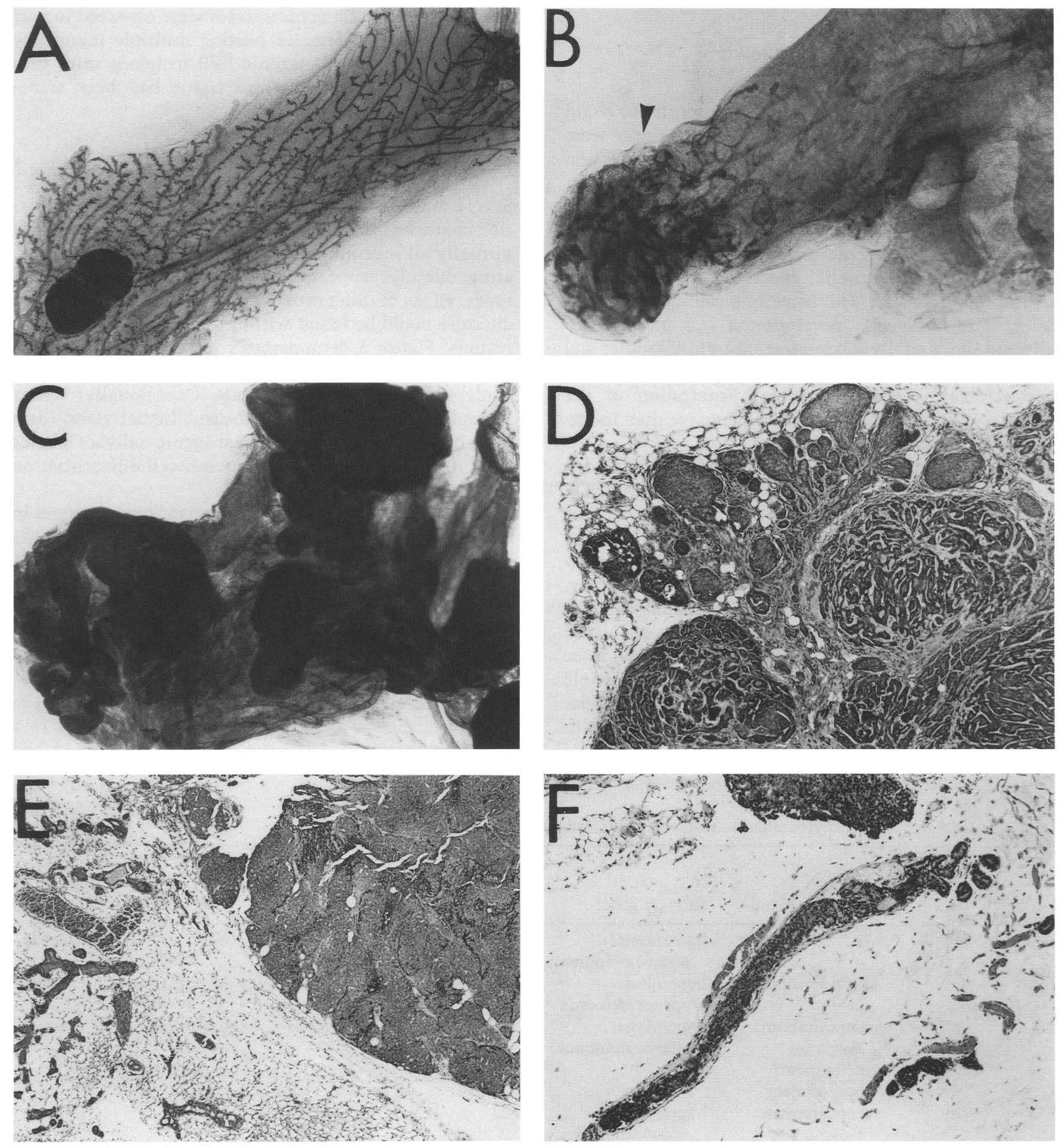

Figure 2. Effects of activated int-3 expression on the mammary gland. $(A-C)$ Whole-mount preparations of mammary glands from adult virgin female mice. $(A)$ Abdominal gland from nontransgenic FVB mouse exhibiting complete penetration of the fat pad by the epithelial ducts; $(B)$ abdominal fat pad from transgenic 5-month-old FFl founder exhibiting arrested ductal penetration $($ arrowhead $) ; C)$ thoracic gland from FF1 founder containing bizarre multifocal nodular structures. $(D-F)$ Histologic analysis of mammary glands from int-3 FF1 transgenic mice. $(D)$ Higher magnification of sections from the whole mount in $C$, showing premalignant hyperplastic lesions; $(E)$ poorly differentiated mammary adenocarcinoma adjacent to ducts and ductules within the fat pad; $(F)$ higher magnification of a duct from the same section shown in $E$, exhibiting intraductal hyperproliferation of the epithelium to form a solid cord of cells completely filling the ductal lumen. Magnifications: $(A-C) 5.7 \times ;(D) 82 \times ;(E) 41 \times ;(F) 164 \times$. 

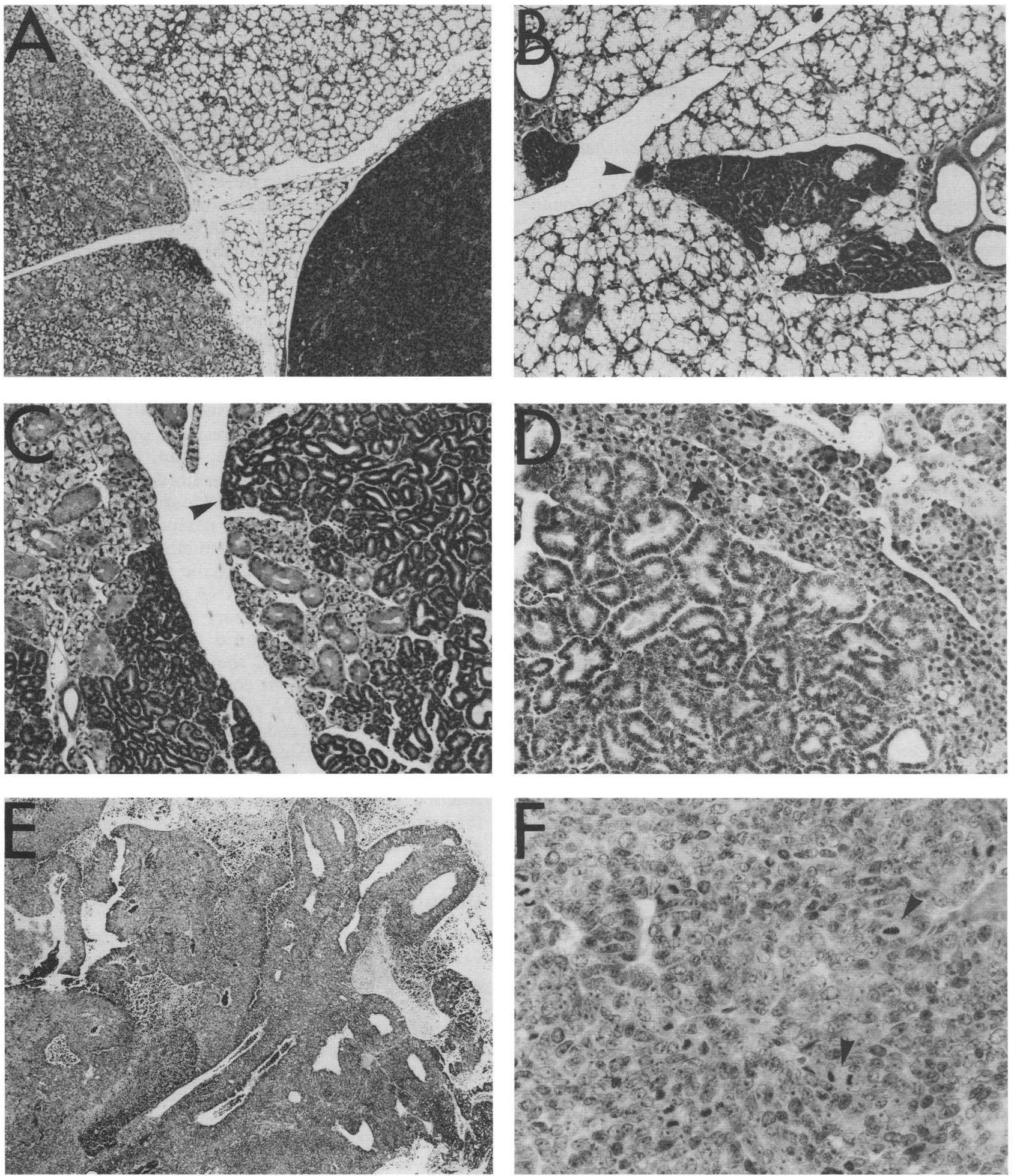

Figure 3. Histologic analysis of int-3 male transgenic salivary glands. (A) Salivary glands of nontransgenic mouse, including submandibular (left), sublingual (top), and parotid (right) glands. Hyperplastic immature ductule cells (arrowheads) of the sublingual gland $(B)$ and the submandibular gland $(C)$ from the 7-month-old AM3 male founder, and the parotid gland $(D)$ from the 6-month-old HM5 male founder. $(E)$ Poorly differentiated salivary adenocarcinoma from AM3. $(F)$ Higher magnification of the salivary tumor shown in $E$, exhibiting neoplastic cells with numerous mitotic figures (arrowheads). Magnifications: $(A) 50 \times ;(B, C) 101 \times .(D) 162 \times ;(E) 40 \times ;(F)$ $324 \times$. 
possessed numerous mitotic figures (Fig. 3F), some of which were abnormal. The AM3 salivary tumor was shown to be malignant by successful transplantation into female nontransgenic syngeneic FVB mice by subcutaneous injection. Although many of the primary salivary tumors exhibited histologically invasive properties, no metastatic lesions were observed.

\section{Ductular hyperplasia in various glandular epithelia of int-3 mice}

Hyperplasia of immature ductule cells was also found frequently in glands associated with the eyes of adult and juvenile int-3 mice (Table 1), including the extraorbital lacrimal gland and the Harderian gland (Fig. 4G and $H$, respectively). Furthermore, in a single FF1 male mouse a tumor developed on one side of the skull; histologic analysis identified the presence of an adenocarcinoma that could have arisen from either the extraorbital lacrimal gland or a minor salivary gland.

All int-3 transgenic mice examined possessed proliferating immature ductules in the glands of the maxillary sinus near the tooth (Fig. 4, cf. C with D) and adjacent to the nasal septum (Fig. 4, cf. E with F), including adult founders AM3, EM1-3, and HM5 and progeny of FF1 as young as 16 days of age; these lesions were never observed in nontransgenic FVB mice. Furthermore, founder EM1-3 developed an adenoma of the nasal mucosa /data not shown).

A number of additional hyperproliferative lesions have been observed sporadically in individual int-3 animals. For example, founder HM5 demonstrated mild preputial gland hyperlasia, founder EM1-3 exhibited focal hyperplasia of the follicular epithelium of the thyroid, a single 7-week-old FF1 male developed lymphoblastic lymphoma of the thymus, and another FFl male exhibited mild multifocal epithelial hyperplasia of the coagulating gland. Furthermore, the GF1 founder died of what appeared to be an autoimmune syndrome, exhibiting glomerulitis, widespread inflammation, infiltration, and edema. The relationship of these lesions to the expression of the activated int -3 gene remains to be elucidated.

\section{int-3 males exhibit severe epididymal hyperplasia} and sterility

int-3 male mice were capable of mating, but on no occasion did any of the plugged females become pregnant. To determine the cause of the observed male sterility, reproductive organs of several male int -3 mice were subjected to histologic analysis. No significant lesions were observed in the testes of any of the male int- 3 mice except for the 7-month-old AM3 founder mouse, which exhibited mild hyperplasia of the interstitial cells and diffuse necrosis and mineralization of the seminiferous tubules. The epididymis of every int -3 male contained severely hyperplastic and disorganized pseudostratified epithelium with a high cellular content (Fig. 4, cf. A with B). This tubular hyperplasia of the epididymis was always associated with the formation of numerous lumens or pseudolumens (Fig. 4B). The transgenic epididymis occasionally appeared to possess a reduced sperm count compared to its normal counterpart. Universal male sterility in int-3 transgenic mice could well be accounted for by the complete penetrance of these epididymal lesions.

\section{Activated int-3 expression correlates with tissue pathogenesis}

The relationship between the expression of the activated int-3 gene and recurrent, tissue-specific pathogenesis was confirmed using total RNA prepared from a variety of organs of both male and female mice of the FF1 line, as well as from various tumor tissues. By an antisense RNase protection assay, the int -3 transgene was found to be highly expressed in a number of tissues, including the Harderian gland, the epididymis, salivary tumors, mammary tumors, and isografts established from transplanted mammary tumors (Fig. 5). However, expression was not detected in other tissues of FF1 line mice, including the testes, seminal vesicles, ovary, liver, pancreas, spleen, skeletal muscle, brain, kidney, thymus, lung, and heart (Fig. 5). These results demonstrate a complete concordance between the tissues expressing the int -3 transgene and those that commonly exhibit developmental or proliferative abnormalities.

To confirm that the transgenic int-3 RNA was the same size as detected in the RNA isolated from the original Czech II mouse mammary tumor from which the genomic fragment was cloned, Northern blot analysis was performed. Figure $1 \mathrm{C}$ shows that the transplanted mammary tumor isograft contained abundant levels of the activated int-3 RNA species of the expected $2.3-\mathrm{kb}$ size; in contrast, the endogenous $6.2-\mathrm{kb}$ int-3 RNA species was not detectable by Northern analysis in this mammary tumor. A highly sensitive polymerase chain reaction (PCR) assay was necessary to detect endogenous int-3 RNA sequences in normal lactating mammary gland (D. Gallahan and R. Callahan, unpubl.).

\section{Discussion}

This study demonstrates that in vivo expression of activated int-3 induces multiple dramatic hyperproliferative and developmental anomalies. Transgenic mice expressing an activated int- 3 gene frequently exhibit intraductal hyperplasia of mammary epithelium and development of poorly differentiated adenocarcinomas of the mammary gland. These findings strongly suggest that the activated int -3 gene product was a contributing factor in the development of those Czech II mouse mammary tumors in which the MMTV-induced rearrangement of the int-3 locus was originally observed (Gallahan and Callahan 1987). Moreover, activated int-3 profoundly restricts mammary alveolar-lobular development, as well as the normal penetration of epithelial ducts into the mammary fat pad. Numerous additional transgenic tissues exhibit severe epithelial hyperplasia and abnormal organogenesis, including the salivary glands, the lacrimal 

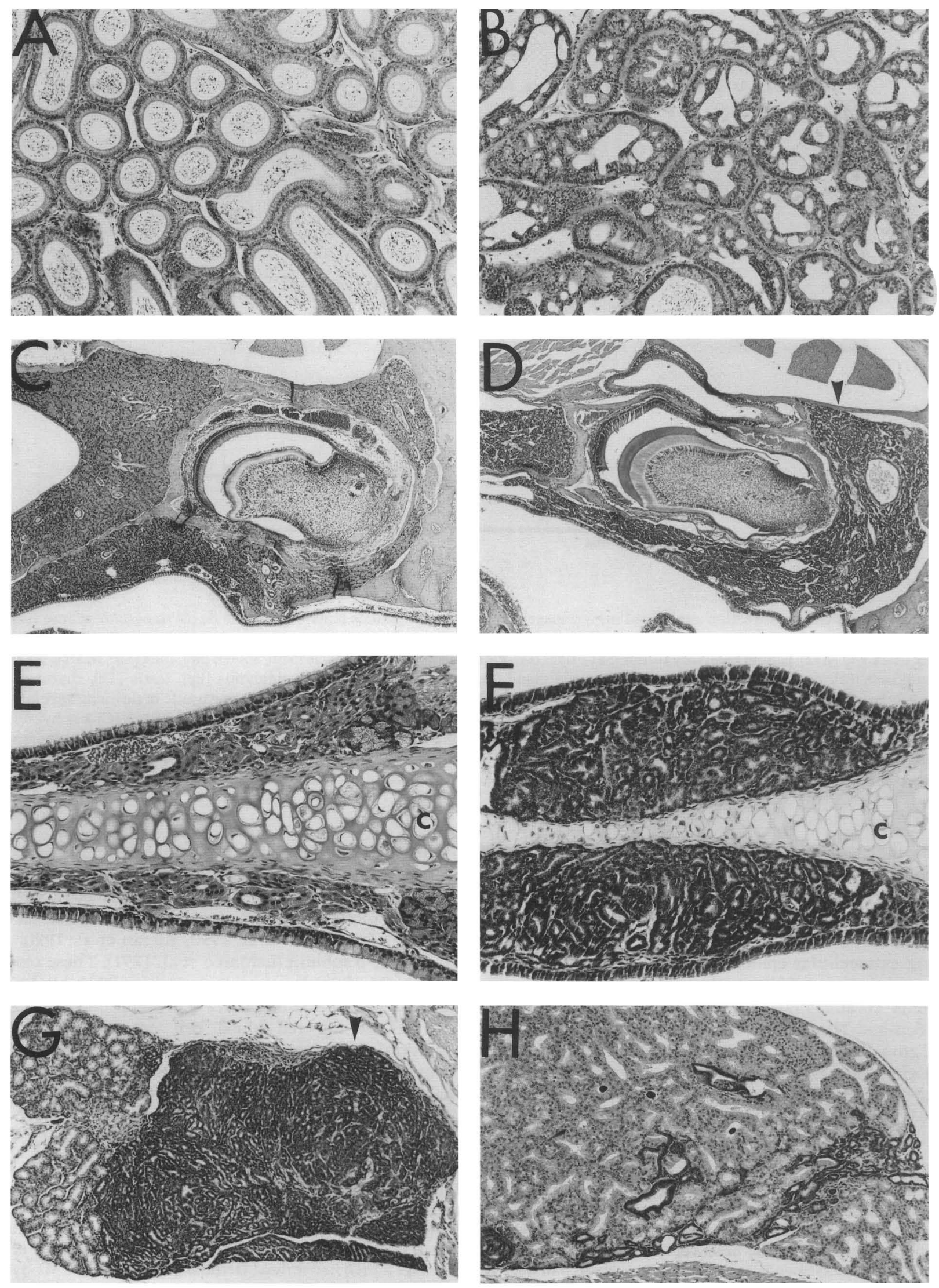

Figure 4. (See following page for legend.) 


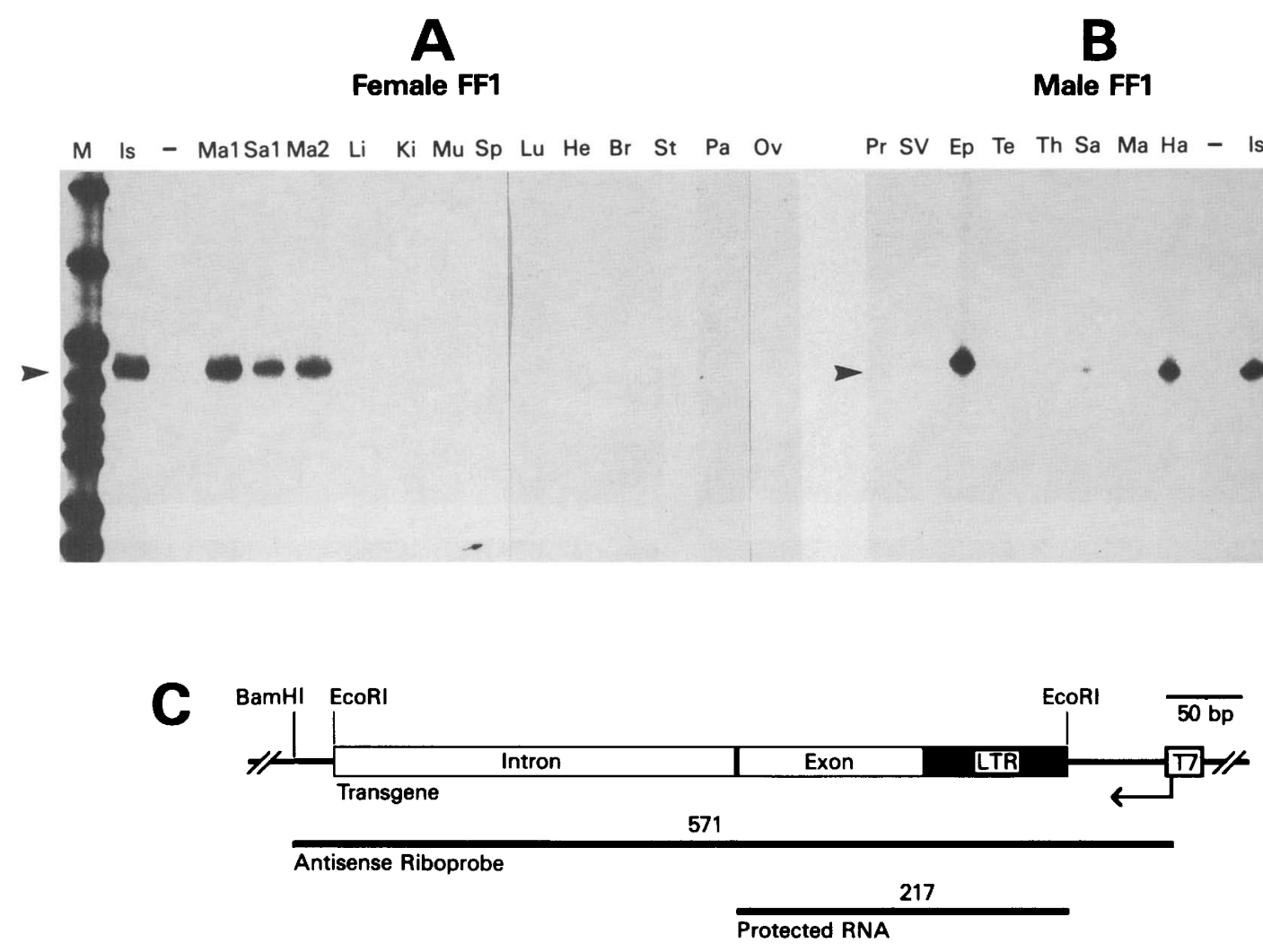

Figure 5. Ribonuclease protection analysis of int-3 transgene expression in various female $(A)$ and male $(B)$ transgenic mouse tissues. Total RNAs were isolated from tissues of int-3 transgenic FFl mice, including a mammary tumor isograft (Is), primary mammary tumors (Ma1 and Ma2), primary salivary tumor (Sal), liver (Li), kidney (Ki), skeletal muscle (Mu), spleen (Sp), lung (Lu), heart (He), brain $(\mathrm{Br})$, stomach $(\mathrm{St})$, pancreas $(\mathrm{Pa})$, ovary $(\mathrm{Ov})$, preputial gland $(\mathrm{Pr})$, seminal vesicle $(\mathrm{SV})$, epididymis (Ep), testis (Te), thymus (Th), nontumor-bearing salivary glands $(\mathrm{Sa})$, and Harderian gland $(\mathrm{Ha})$. Negative control RNAs were from transgenic male mammary fat pads (Ma), and nontransgenic FVB liver (-1. A 571-base ${ }^{32}$ P-labeled antisense riboprobe specific for transgenic int-3 RNA (C) was hybridized to $15 \mu \mathrm{g}$ of total tissue RNAs and incubated with RNases $\mathrm{A}$ and $\mathrm{T} 1$, and the resulting 217-base radiolabeled protection products were analyzed by denaturing $6 \%$ polyacrylamide gel electrophoresis and autoradiography $(A, B)$. Markers $(M)$ are $404,309,242,238,217,201$, 190, 180, 160, and 147 bases in length. Arrowheads indicate the expected size of the transgene-specific int-3-protected RNA.

glands, the Harderian glands, glands of the nasal mucosa and maxillary sinus, and the epididymis.

The murine int-3 gene is similar in structure and sequence to the Drosophila Notch gene (Wharton et al. 1985 ) in that it encodes a transmembrane protein containing extracellular epidermal growth factor (EGF) repeats and six copies of intracellular $c d c 10 / S W 16$ repeats (Robbins et al. 1992). The cdc10/SWI6 repeat motif (Breeden and Nasmyth 1987a) has been found in a diverse group of proteins implicated in signal transduction regulating cell growth and differentiation, including Notch (Wharton et al. 1985), and lin-12 and glp-1 of Caenorhabditis elegans (Yochem and Greenwald 1989). The yeast SWI6 and SWI4 proteins are DNA-binding proteins (Breeden and Nasmyth 1987b; Andrews and Herskowitz 1989|; more recently, cdc10/SWI6 repeat sequences have also been found in the mammalian transcription factors $N F-\kappa B / K B F 1$ (Bours et al. 1990; Kieran et al. 1990) and the GABP $\beta$ subunit (LaMarco et al. 1991). These repeats in the $G A B P \beta$ subunit are essential for DNA binding to the Ets-related subunit $G A B P \alpha$ (Thompson et al. 1991). Studies of the red blood cell cytoskeletal protein ankyrin, another protein possessing $c d c 10 / S$ WI6 repeat sequences, further supports the idea that they are important in protein-protein interaction (Lux et al. 1990).

The human homolog of the Notch gene, TAN-1 (El-

Figure 4. Histologic analysis of atypical glandular epithelia of int-3 transgenic mice. Epididymis of nontransgenic FVB $(A)$ and FF1 int -3 adult $(B)$ mice. Note formation of pseudolumens and disorganized hyperplastic lesions in transgenic epididymis. The nasal mucosa near the lateral wall of the tooth from nontransgenic $(C)$ and EM1-3 int-3 adult male $(D)$ mice. Note severe ductular hyperplasia (arrowhead). The nasal septum from nontransgenic $(E)$ and AM3 int -3 adult $(F)$ males. Note severe hyperplasia of the mucosal/submucosal glands and resulting compression of the hyalin cartilage (c). (G) Extraorbital lacrimal gland from the EM1-3 int-3 transgenic founder, exhibiting diffuse severe ductular hyperplasia (arrowhead). $(H)$ Harderian gland from an FF1 int-3 adult male, showing multifocal hyperplastic lesions (i.e., arrowhead). Magnifications: $(A, B, G, H) 73 \times ;(C, D) 36 \times ;(E, F) 146 \times$. 
lisen et al. 1991), recently has been shown to be translocated in acute T-lymphoblastic leukemia (T-ALL), resulting in truncation and overexpression of TAN-1 transcripts encoding a $c d c 10 /$ SWI6 motif-bearing protein. Furthermore, another human gene encoding cdc10/ $S W 16$ repeat sequences, $b c l-3$, has been localized to a chromosomal translocation breakpoint associated with chronic lymphocytic leukemia (Ohno et al. 1990). This circumstantial evidence suggests that disruption or deregulation of proteins containing the highly conserved cdc10/SW16 repeats may play a role in cellular proliferation and/or tumorigenesis. This hypothesis, however, has not been tested in vivo. In this report results are presented that provide biological evidence demonstrating in vivo that an activated int -3 transcript bearing coding sequence for a $c d c 10 / S W I 6$-related protein is highly oncogenic in transgenic mice.

The mechanism whereby activated int-3 promotes malignant transformation is unknown. If, by analogy with Notch, the extracellular EGF-like domain of int-3 is involved in ligand recognition and binding and the intracellular cdc10/SWI6 domain functions in some form of signal transduction, then the primary consequence of MMTV integration would be to produce a truncated signal-transducing int-3 protein released from the normal regulatory controls provided by the ligand-binding domain. The notion that such a signal might convey developmental information is supported by the findings that int -3 is a member of the Notch gene family, that juvenile mice bearing the activated int -3 transgene possess abnormal mammary glands in which the development of end buds and alveolar-lobular structures is dramatically reduced or absent, and that both simple and compound exocrine glands expressing the activated int -3 transgene appear to be incompletely differentiated and possess proliferating immature ductule cells. In this hypothetical scenario, expression of activated int-3 would interfere with the terminal differentiation of specific epithelial cell types, resulting in aberrant organogenesis and the appearance of atypical morphologic patterns. Proliferating immature ductule cells were already evident in juvenile 16-day-old transgenic mice, suggesting that activated int -3 expression alone may be sufficient to perturb normal developmental processes.

Irrespective of the mechanism of action, it is likely that int-3 alone is not sufficient for full neoplastic transformation and that additional genetic events may be necessary. Malignant cancers of the mammary and salivary glands in int-3 transgenic mice appear stochastically in adult mice, and in some glands tumors fail to develop during the abbreviated lifetime of the transgenic host. Similarly, individual activation of expression of either Wnt-1 (Tsukamoto et al. 1988) or int-2 (Muller et al. 1990 ) is not sufficient for malignant transformation of mammary epithelium but does induce hyperplasia of the alveolar-lobular structures of the gland from which focal mammary adenocarcinomas arise. This is in striking contrast to mammary lesions in activated int-3 transgenic mice, where the formation of alveolar-lobular structures is suppressed. It seems clear that mammary carcinogenesis must be, at least in part, a consequence of the collaborative effects of multiple mutations. MMTVinduced activation of $W n t-1$ and int-2 frequently occurs together in the mammary tumors of certain inbred mouse strains (Peters et al. 1986). Coactivation of Wnt-1 or int-2 and int-3 has also been observed in some mammary tumors (Peters et al. 1989). The availability of transgenic mouse strains containing activated constructs of each of these genes will provide an opportunity to assess the collaborative effects of the expression of these genes on mammary gland development and tumorigenesis.

\section{Materials and methods}

Plasmids and preparation of DNA for microinjection

Transgenic mice were generated using a $7.5-\mathrm{kbp}$ genomic DNA fragment containing the $3^{\prime}$ portion of the mouse int-3 gene under the influence of the Czech II MMTV LTR /Gallahan and Callahan 1987). This fragment was isolated from the plasmid pAl (Fig. 1A) by digestion with EcoRI, which releases the 7.5$\mathrm{kbp}$ int 3 fragment from the $2.7-\mathrm{kbp}$ pUC13 vector. After EcoRI digestion, the fragment was prepared for microinjection into mouse embryos using sucrose gradient centrifugation, as described previously (Jhappan et al. 1990).

A second plasmid (51/52 pA1) was prepared for riboprobe synthesis by subcloning a 217 -bp fragment containing a fraction of the LTR and adjacent int-3 sequences (Fig. 3) into the Bluescript plasmid pBS (Stratagene). T7 polymerase was then used to generate antisense riboprobes for RNase protection assays.

\section{Generation and maintenance of transgenic mice}

Single-cell mouse embryos were harvested from the inbred FVB/N strain of mice (Harlan Sprague Dawley, Inc., Frederick, $\mathrm{MD}$ ). The purified $7.5-\mathrm{kbp}$ int-3 fragment was microinjected into the pronuclei of these embryos at a concentration of 0.5 $\mu \mathrm{g} / \mathrm{ml}$ (Hogan et al. 1986). Embryos surviving microinjection were transferred to the oviducts of pseudopregnant CD1 females (Charles River Labs). To identify the resulting transgenic progeny, genomic DNA was isolated from tail biopsies, digested with $\mathrm{BamHI}$, electrophoresed on an $0.8 \%$ agarose gel, and hybridized to the int-3 probe $21 / 22$, which was made using PCR (Fig. 1A).

Although all int -3 transgenic males were sterile and all int-3 transgenic females were incapable of nurturing their pups, a line of int -3 transgenic mice was established by superovulating and mating the female founder FF1 to a nontransgenic FVB male, isolating single-cell embryos, and transferring them to a pseudopregnant CDl female mouse. Thereafter, mice newly born to subsequent FF1 int-3 transgenic mice were routinely moved to foster mothers.

\section{RNA preparation and analysis}

RNA was prepared from a variety of mouse tissues as described previously (Chomczynski and Sacchi 1987). All tissues were removed, frozen immediately on dry ice, and subsequently homogenized in a $4 \mathrm{~m}$ guanidine isothiocyanate solution. The tissue homogenate was then acid-phenol-extracted and total RNAprecipitated using isopropanol. The RNA was further deproteinated with phenol-chloroform extractions and precipitated with ethanol.

To detect expression of the int-3 transgene in mice generated 
in this study, $15 \mu \mathrm{g}$ of total RNA was used in RNase protection assays (Promega) and Northern blot analyses that were performed as described previously (Thomas 1980; Jhappan et al. 1990; Merlino et al. 1991). Probe 21/22 labeled with ${ }^{32} \mathrm{P}$ (Fig. 1A) was used for Northern blot hybridization, and plasmid $51 / 52$ pA1 was used for RNase protection assays. The RNase protection assay was performed by first linearizing $51 / 52$ pAl with $B a m H I$ and then transcribing it in the presence of $\left[\alpha^{-32} \mathrm{P}\right]$ GTP using its T7 promoter. The resulting ${ }^{32} \mathrm{P}$-labeled 571-base RNA probe was incubated overnight with total tissue RNA at $52^{\circ} \mathrm{C}$ and digested with RNases A and $\mathrm{T} 1$ for $1 \mathrm{hr}$ at $30^{\circ} \mathrm{C}$. A 217-base radiolabeled fragment was protected from RNase digestion, electrophoresed on a denaturing $6 \%$ polyacrylamide gel, and visualized by autoradiography.

\section{Preparation of tissue for histology}

Tissues were routinely fixed in $10 \%$ buffered formalin, embedded in paraffin, thin-sectioned, and stained with hematoxylin and eosin. Mammary tissue prepared for whole-mount analysis was first fixed in $10 \%$ buffered formalin, cleared of fatty tissue in acetone, stained in hematoxylin, cleared with xylene, and stored in methyl salicylate.

\section{Acknowledgments}

We thank Drs. Miriam Anver and Robert Kovatch for evaluating the histopathology of tissues from the transgenic mice, Robert Linton, Richard Sharp, and David McCurdy for their expert technical assistance, and Drs. Hitoshi Takagi, Michael Gottesman, Ira Pastan, and Elisa Durban for useful discussions.

The publication costs of this article were defrayed in part by payment of page charges. This article must therefore be hereby marked "advertisement" in accordance with 18 USC section 1734 solely to indicate this fact.

\section{References}

Andrews, B.J. and I. Herskowitz. 1989. Identification of a DNA binding factor involved in cell-cycle control of the yeast $\mathrm{HO}$ gene. Cell 57: 21-29.

Aves, S.J., B.W. Durckacz, A. Carr, and P. Nurse. 1985. Cloning, sequencing and transcriptional control of the Schizosaccharomyces pombe cdc10 "start" gene. EMBO /. 4: 457-463.

Bours, V., J. Villalobos, P.R. Burd, K. Kelly, and U. Siebenlist. 1990. Cloning of a mitogen-inducible gene encoding a $\mathrm{kB}$ DNA-binding protein with homology to the rel oncogene and to cell-cycle motifs. Nature 348: 76-80.

Breeden, L. and K. Nasmyth. 1987a. Cell cycle control of the yeast $H O$ gene: Cis- and trans-acting regulators. Cell 48: $389-397$.

- $1987 \mathrm{~b}$. Similarity between cell-cycle genes of budding yeast and fission yeast and the Notch gene of Drosophila. Nature 329: 651-654.

Chomczynski, P. and N. Sacchi. 1987. Single-step method of RNA isolation by acid guanidinium thiocyanate-phenolchloroform extraction. Anal. Biochem. 162: 156-159.

Coffman, C., W. Harris, and C. Kintner. 1990. Xotch, the Xenopus homolog of Drosophila notch. Science 249: 1438-1441.

Dickson, C. and G. Peters. 1987. Potential oncogene product related to growth factors. Nature 326: 833 .

Dickson, C., R. Smith, S. Brookes, and G. Peters. 1984. Tumorigenesis by mouse mammary tumor virus: Proviral activation of a cellular gene in the common integration region int-2. Cell 37: 529-536.
Ellisen, L.W., J. Bird, D.C. West, A.L. Soreng, T.C. Reynolds, S.D. Smith, and J. Sklar. 1991. TAN-1, the human homolog of the Drosophila notch gene, is broken by chromosomal translocations in T lymphoblastic neoplasms. Cell 66: 649661 .

Gallahan, D. and R. Callahan. 1987. Mammary tumorigenesis in feral mice: Identification of a new int locus in mouse mammary tumor virus (Czech II)-induced mammary tumors. I. Virol, 61: 66-74.

Greenspan, R.J. 1990. The Notch gene, adhesion, and developmental fate in the Drosophila embryo. New Biol. 2: 595600.

Hogan, B., F. Costantini, and E. Lacy. 1986. Manipulating the mouse embryo: A laboratory manual. Cold Spring Harbor Laboratory, Cold Spring Harbor, New York.

Jhappan, C., C. Stahle, R.N. Harkins, N. Fausto, G.H. Smith, and G.T. Merlino. 1990. TGF $\alpha$ overexpression in transgenic mice induces liver neoplasia and abnormal development of the mammary gland and pancreas. Cell 61: 1137-1146.

Kieran, M., V. Blank, F. Logeat, J. Vandekerckhove, F. Lottspeich, O. Le Bail, M.B. Urban, P. Kourilsky, P.A. Baeuerle, and A. Israel. 1990. The DNA binding subunit of NF- $\mathrm{kB}$ is identical to factor KBF1 and homologous to the rel oncogene product. Cell 62: 1007-1018.

LaMarco, K., C.C. Thompson, B.P. Byers, E.M. Walton, and S.L. McKnight. 1991. Identification of Ets- and notch-related subunits in GA binding protein. Science 253: 789-792.

Lux, S.E., K.M. John, and V. Bennett. 1990. Analysis of cDNA for human erythrocyte ankyrin indicates a repeated structure with homology to tissue-differentiation and cell-cycle proteins. Nature 344: 36-42.

Merlino, G.T., C. Stahle, C. Jhappan, R. Linton, K.A. Mahon, and M.C. Willingham. 1991. Inactivation of a sperm motility gene by insertion of an epidermal growth factor receptor transgene whose product is overexpressed and compartmentalized during spermatogenesis. Genes \&) Devel. 5: 13951406.

Muller, W.J., F.S. Lee, C. Dickson, G. Peters, P. Pattengale, and P. Leder. 1990. The int-2 gene product acts as an epithelial growth factor in transgenic mice. EMBO J. 9: 907-913.

Nusse, R. and H. E. Varmus. 1982. Many tumors induced by the mouse mammary tumor virus contain a provirus integrated in the same region of the host genome. Cell 31: 99-109.

Ohno, H., G. Takimoto, and T.W. McKeithan. 1990. The candidate proto-oncogene $b c l-3$ is related to genes implicated in cell lineage determination and cell cycle control. Cell 60: 991-997.

Peters, G., A.E. Lee, and C. Dickson. 1986. Concerted activation of two potential proto-oncogenes in carcinomas induced by mouse mammary tumor virus. Nature 320: 628-631.

Peters, G., S. Brookes, R. Smith, M. Placzek, and C. Dickson. 1989. The mouse homolog of the hst/k-FGF gene is adjacent to int-2 and is activated in some virally induced mammary tumors. Proc. Natl. Acad. Sci. 86: 5678-5682.

Rijsewijk, F., M. Schuermann, E. Wagenaar, P. Parren, D. Weigel, and R. Nusse. 1987. The Drosophila homolog of the mouse mammary oncogene int-1 is identical to the segment polarity gene wingless. Cell 50: 649-657.

Robbins, J., B.J. Blondel, D. Gallahan, and R. Callahan. 1992. Mouse mammary tumor gene int-3: A member of the notch gene family transforms mammary epithelial cells. $J$. Virol. (in press).

Rogers, S., R. Wells, and M. Rechsteiner. 1986. Amino acid sequences common to rapidly degraded proteins: The PEST hypothesis. Science 234: 364-368.

Spence, A.M., A. Coulson and J. Hodgkin. 1990. The product of 
fem-1, a nematode sex-determining gene, contains a motif found in cell cycle control proteins and receptors for cell-cell interactions. Cell 60: 981-990.

Thomas, P.S. 1980. Hybridization of denatured RNA and small DNA fragments transferred to nitrocellulose. Proc. Natl. Acad. Sci. 77: 5201-5205.

Thompson, C.C., T.A. Brown, and S.L. McKnight. 1991. Convergence of Ets- and notch-related structural motifs in a heteromeric DNA binding complex. Science 253: 762-768.

Tsukamoto, A.S., R. Grosschedl, R.C. Guzman, T. Parslow, and H.E. Varmus. 1988. Expression of the int-1 gene in transgenic mice is associated with mammary gland hyperplasia and adenocarcinomas in male and female mice. Cell 55: 619-625.

Varmus, H.E. 1982. Recent evidence of oncogenesis by insertional mutagenesis. Cancer Surv. 1: 309-320.

Weinmaster, G., V.J. Roberts and G. Lemke. 1992. A homolog of Drosophila notch expressed during mammalian development. Development 113: 199-205.

Wharton, K.A., K.M. Johansen, T. Xu, and S. Artavanis-Tsakonas. 1985. Nucleotide sequence from the neurogenic locus notch implies a gene product that shares homology with proteins containing EGF-like repeats. Cell 43: 567-581.

Yochem, J. and I. Greenwald. 1989. Glp-1 and lin-12, genes implicated in distinct cell-cell interactions in C. elegans, encode similar transmembrane proteins. Cell 58: 553-563. 


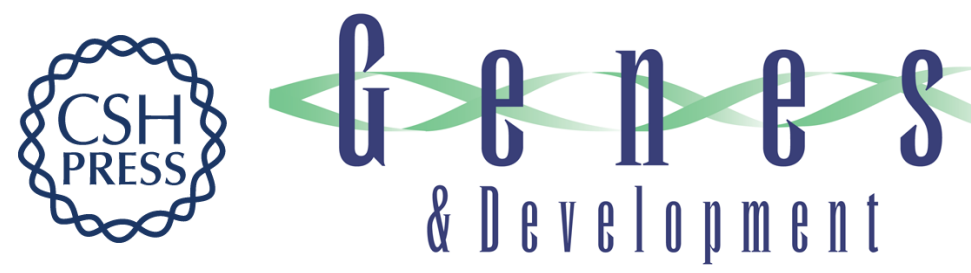

\section{Expression of an activated Notch-related int-3 transgene interferes with cell differentiation and induces neoplastic transformation in mammary and salivary glands.}

C Jhappan, D Gallahan, C Stahle, et al.

Genes Dev. 1992, 6:

Access the most recent version at doi:10.1101/gad.6.3.345

References This article cites 32 articles, 8 of which can be accessed free at: http://genesdev.cshlp.org/content/6/3/345.full.html\#ref-list-1

License

Email Alerting Service

Receive free email alerts when new articles cite this article - sign up in the box at the top right corner of the article or click here.

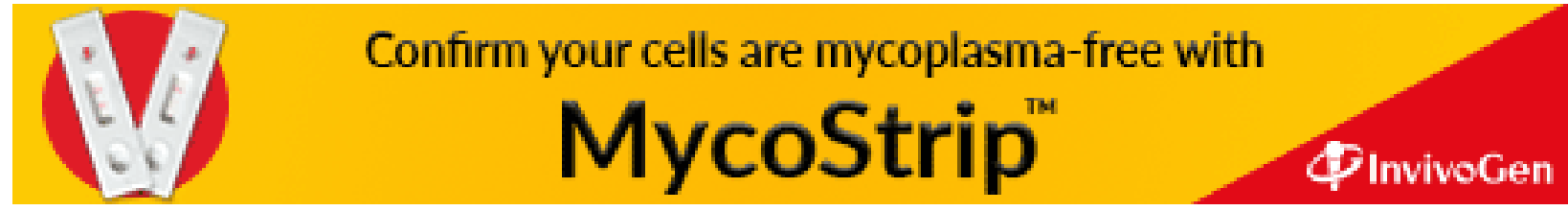

